Journal of the

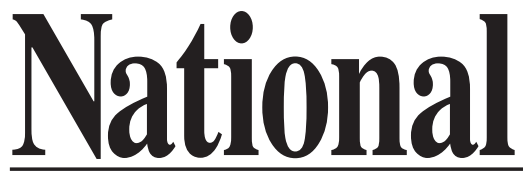

Academy or

Forensic
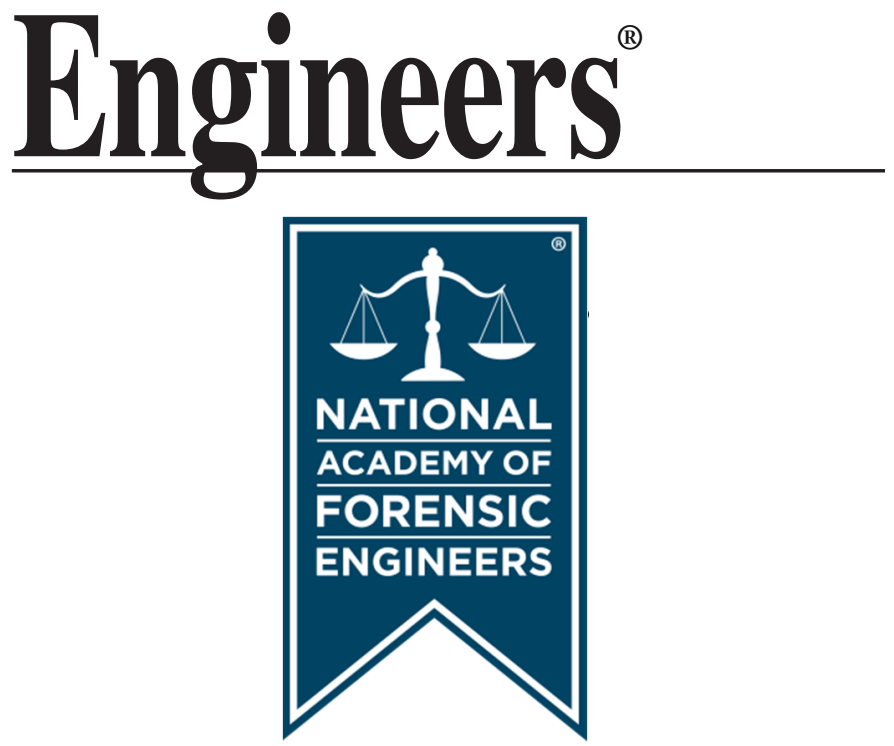

http://www.nafe.org ISSN: 2379-3252 


\title{
Forensic Engineering Investigations of Product Liability Cases
}

by Richard M. Ziernicki, Ph.D., P.E. (NAFE 308F)

Ben T. Railsback, P.E. (NAFE 713M)

\begin{abstract}
Engineers are regularly retained to perform investigations to determine whether or not a product is defective and liable for injuries sustained by an individual or damages by a commercial entity. While engineers are trained to solve problems based on physical principles, little training is given to the graduate engineer to determine whether a product is "defective" or not. Since the majority of product liability actions result from an injury sustained by an individual using a product, the engineer is ultimately evaluating the safety of the product. The authors of this paper will detail a general methodology to investigate product liability claims through the use of safety engineering principles.
\end{abstract}

\section{Keywords}

Forensic Engineering, Product Liability, Hazard, Risk, Safety

\section{Introduction}

The forensic engineer investigating whether a product is defective will determine whether or not a hazard exists with a product. After establishing that a hazard exists with the product, the investigating engineer can utilize a hierarchy of engineering principles, to determine whether or not the injury associated with the hazard could and should have been prevented. The engineer will determine first whether redesigning the product could have prevented or reduced the risk associated with the hazard. If the hazard cannot be reduced or eliminated by redesigning the product, the engineer will examine whether or not safety features to guard against the hazard could have prevented the accident. If design and guarding cannot eliminate or mitigate the risk of the hazard sufficiently, the engineer should examine whether or not warnings would have prevented the accident. When the investigating engineer can conclude that the hazard was known or foreseeable, that the risk associated with the hazard was unacceptable, and that personal injuries would have been eliminated or significantly reduced had the engineering hierarchy been properly applied, then the engineer can conclude that the product was defective. 
Copyright @ National Academy of Forensic Engineers (NAFE) http://www.nafe.org. Redistribution or resale is illegal Originally published in the Journal of the NAFE volume indicated on the cover page. ISSN: 2379-3252

Forensic engineers may also utilize the above methodology when they are retained to examine whether or not a claim that a product is defective can be disputed. The engineer might be able to establish that the hazard was not known and not foreseeable, that the risk associated with the product was acceptable, that it was not economically and technically feasible to design the product to prevent the hazard, that guarding and/or safety devices cannot prevent or reduce the hazard, and that the injured party either would not have benefitted from warnings or ignored warnings. When the investigating engineer can prove that one or more of these factors are true, the engineer can conclude that the product is not defective and unreasonably dangerous.

This paper will first outline a few of the legal theories of product liability including negligence, strict liability, and breach of warranty. ${ }^{1}$ The key elements of a product liability action will be briefly examined. The paper will then focus on safety engineering principles and their application to product liability investigations. Finally two case studies of product liability investigation will be presented to demonstrate how the principles of safety engineering can be applied.

\section{Legal Theories of Product Liability}

The negligence theory of product liability focuses on the behavior of the manufacturer (Weinstein 6). In essence, negligence claims that the conduct or the behavior of the manufacturer of a particular product fell below a reasonable standard of care and exposed a party to an unreasonably great risk. It is inherent in this definition that real risks exist with the use of products. Negligence actions will focus on technology available (at a reasonable price) at the time that the product is manufactured to determine whether the product is defective. It will be assumed that the manufacturer knew, or should have known, about technology available to produce a reasonably safe product. The manufacturer can rely on internal standards, consensus or voluntary standards, and statues to demonstrate that the product complied with known safety standards; however, such standards only establish that minimum requirements have been met. Compliance with standards does not show that the manufacturer is not negligent. Ultimately, the issue that is addressed is whether the risk associated with the product is justified or reasonable.

In contrast to the negligence principle, strict liability focuses on the product itself rather than the behavior of the manufacturer (Weinstein 8). The safety of the product and whether or not the product is unreasonably dangerous will be the focus of litigation. Strict liability claims will focus on whether or not the product is reasonably safe in the environment intended for use.

The theory of breach of warranty focuses on the representations or claims that have been made regarding the product (Weinstein 11). Three theories of warranty exist. The theory of express warranty, implied warranty of merchantability, and 
Copyright @ National Academy of Forensic Engineers (NAFE) http://www.nafe.org. Redistribution or resale is illegal. Originally published in the Journal of the NAFE volume indicated on the cover page. ISSN: 2379-3252

NAFE 308F/713M

INVESTIGATIONS OF PRODUCT LIABILITY

PAGE 53

implied warranty of fitness. Express warranties are direct statements about the product made by the manufacturer while implied warranties are based on the circumstances of the sale of the product. Implied warranty of merchantability and implied warranty of fitness are warranties that the product is suitable for the buyer's purpose or fit for the ordinary purposes of the product unless those purposes are specifically disclaimed by the manufacturer. This paper will primarily focus on investigations based on negligence and strict liability claims.

\section{Basic Elements of a Product Liability Action}

In a product liability action against a manufacturer, the plaintiff needs to establish several basic elements to be successful (Weinstein 17). The plaintiff must establish that:

- The product was defective.

- That the product was defective at the time it left control of the defendant

- That damages sustained by the plaintiff were a direct result of the defect

Should the plaintiff be unable to prove the above elements, the product liability action will be unsuccessful. Typically the most difficult element for a forensic engineer to establish is whether or not the product is defective.

\section{methodology to Investigate Product Liability Claims}

Safety engineering as a discipline is well suited to evaluating product liability claims in that the safety engineer typically uses knowledge of safety engineering to reduce and control hazards associated with products, processes or work environments. The safety engineer may have training in many diverse disciplines such as mechanical, electrical or chemical engineering, but uses that training and knowledge of safety principles to focus on the prevention and reduction of injuries. Since the focus of the safety engineer is the prevention and reduction of injuries, the tools developed in safety engineering can be used to evaluate the safety and liability of products in an accident.

The safety engineer evaluates products utilizing an engineering hierarchy of safety principles. Practices to control hazards have been prioritized into a hierarchy because it is more desirable to eliminate hazards than to just reduce the risks associated with hazards or providing warnings. The engineer utilizing the hierarchy should also recognize that the process can be iterative. The hierarchy of principles typically utilized is as follows (ISO 12100-1992, ANSI/ASSE Z244.1-2003):

1. Eliminate the hazard by design

2. Provide safety devices (such as guards, barriers, interlocks, failsafe design, etc.) 
Copyright @ National Academy of Forensic Engineers (NAFE) http://www.nafe.org. Redistribution or resale is illegal. Originally published in the Journal of the NAFE volume indicated on the cover page. ISSN: 2379-3252

3. Provide warnings (warnings, cautions, alarms, etc.)

4. Provide training, instructions, personal protective equipment

The forensic engineer investigating product liability claims must first recognize that products should be reasonably safe for their intended use and their foreseeable misuse. After recognizing that the product must be reasonably safe a methodology to evaluate whether or not the product was safe can be used to evaluate whether or not the product is defective. A product liability action focuses on an injury that resulted due to interaction between the plaintiff and a product. Safety engineering defines a hazard as an unsafe condition or the potential for an activity, condition or circumstance to produce a harmful effect. If the plaintiff was truly injured by the product, then a hazard exists with the product. The forensic engineer should investigate whether or not the hazard was known or should have been known to the manufacturer. After establishing whether or not the manufacturer was aware or should have been aware of the hazard, the forensic engineer will establish that the hazard could, or could not have been mitigated through the use of the engineering hierarchy.

The plaintiff in a product liability action must typically show that a product was defective, and that a change in the product would eliminate or reduce the damages experienced by the plaintiff. Use of the engineering hierarchy of safety principles will focus the forensic engineer on options to eliminate or mitigate hazards. However, the forensic engineer must also show that the proposed change in the product is technically and economically feasible. It should also be noted that use of the engineering hierarchy will also include analysis of warnings, and whether or not the manufacturer failed to warn the plaintiff of a hazard. To summarize, the following questions should be asked during the product liability investigation:

1. Was the manufacturer/industry aware of the hazard?

2. Was the risk associated with the hazard unreasonable?

3. Was it technically and economically feasible for the manufacturer to mitigate the hazard associated with the product by:
a. Design?
b. Guarding?
c. Warning?
d. Training and Instructions?
a. All of the above? 
Copyright () National Academy of Forensic Engineers (NAFE) http://www.nafe.org. Redistribution or resale is illegal. Originally published in the Journal of the NAFE volume indicated on the cover page. ISSN: 2379-3252

NAFE 308F/713M

INVESTIGATIONS OF PRODUCT LIABILITY

PAGE 55

\section{Case Studies}

Two case studies will be presented to illustrate how safety engineering principles can be applied to product liability investigations. The first case study involves a product liability claim brought against the manufacturer of a mechanical bull and the second case study involves a hydraulic rough terrain crane. In the first case study, the rider of the mechanical bull was thrown into the air from the bull at a relatively high speed setting, landed on his head, neck, and shoulders on the foam pad supplied with the bull, and suffered a spinal injury as a result. In the second case study, the hydraulic rough terrain crane came into contact with an overhead power line and a concrete bucket attached to the load line became electrified. A construction worker was guiding the bucket when the crane came into contact with the power line. As a result of the incident, the construction worker experienced significant burns, became a triple amputee, and sustained nervous system/brain injuries. Both incidents resulted in product liability claims. The mechanical bull incident was tried to verdict resulting in a decision for the defense, while the plaintiff in the hydraulic crane incident received a favorable settlement prior to a trial.

\section{Case Study \#1 Mechanical Bull - Spinal Injury}

At approximately 10:20 pm, on April 1, 2001, the plaintiff mounted a mechanical bull in a night club located inside a casino in Las Vegas, Nevada. The plaintiff was an employee of the casino, and regularly rode the mechanical bull during his off duty hours. Security video cameras captured the incident in black and white video. Review of the video shows that the plaintiff was an experienced rider, and rode the bull for approximately 30 seconds. As the ride progressed the operator increased the bucking speed of the bull, and increased the rotational speed of the bull, while switching the rotation direction of the bull. When the ride approached the thirty second mark, the plaintiff began to fall off of the bull. Approximately 1 second after the rider began to separate from the bull, the operator stopped the ride. As the plaintiff separated from the bull, he was thrown approximately 6 feet in the air and fell on his head and neck with his body above him. The plaintiff described his body as being in a fetal position when he came into contact with the mat. A witness described the plaintiff as falling in a "pike" position onto his head, neck and shoulders. Figure 1 is a still frame extracted from the video during the ride and Figure 2 is a still frame of the plaintiff when he first came into contact with the mat.

As a result of the fall the plaintiff sustained a flexion-compression cervical spine injury that ruptured discs in the plaintiff's neck. As a result of the incident the plaintiff underwent extensive surgery to fuse vertebrae in his neck. In litigation, the plaintiff alleged that the padding that the plaintiff fell on was inadequate, and that an air mattress should have been used instead. 
Copyright @ National Academy of Forensic Engineers (NAFE) http://www.nafe.org. Redistribution or resale is illegal. Originally published in the Journal of the NAFE volume indicated on the cover page. ISSN: 2379-3252

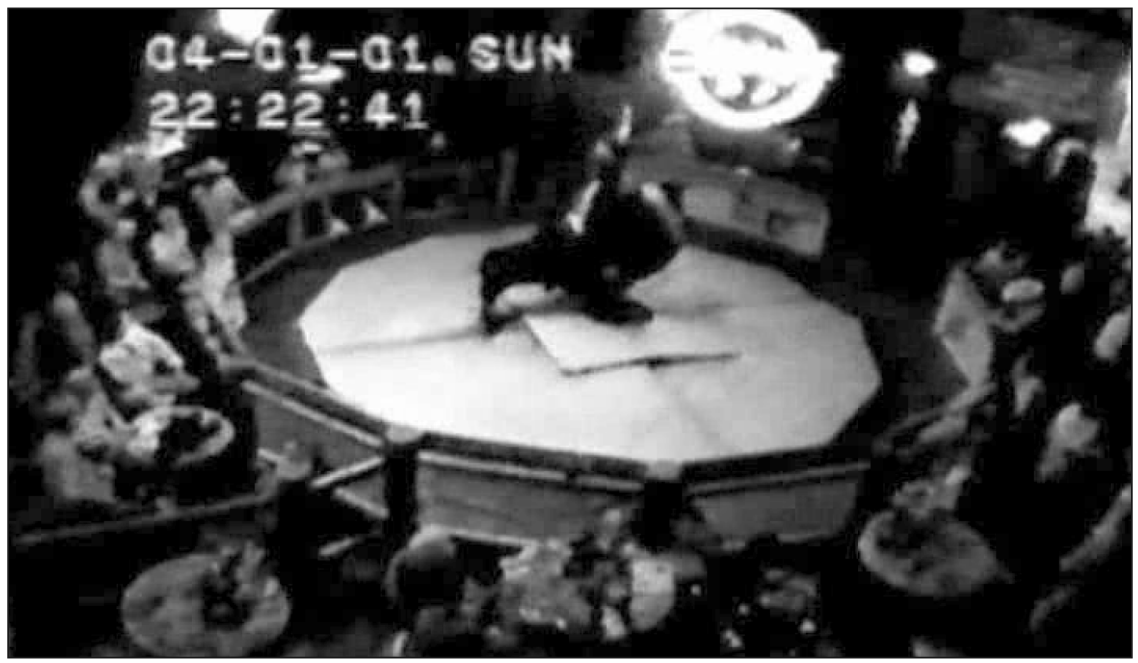

Figure 1

Still Frame from Video of Plaintiff's Ride

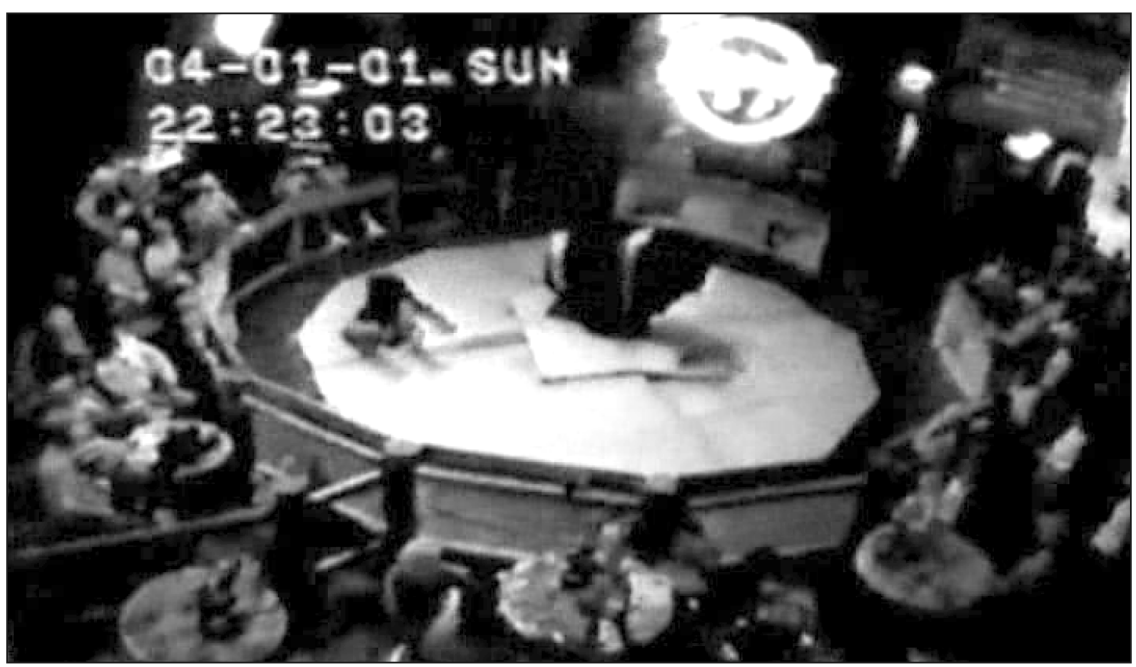

Figure 2

Still Frame of Plaintiff Landing

These engineers were retained to evaluate the case and the claim that the padding surrounding the bull was inadequate. Utilizing the methodology outlined in this paper, these engineers first determined what the hazard associated with the mechanical bull was, whether the manufacture was aware of the hazard, and then evaluated whether it was technically and economically feasible to mitigate the hazard through design, guarding or warnings. 
Copyright @ National Academy of Forensic Engineers (NAFE) http://www.nafe.org. Redistribution or resale is illegal. Originally published in the Journal of the NAFE volume indicated on the cover page. ISSN: 2379-3252

NAFE 308F/713M INVESTIGATIONS OF PRODUCT LIABILITY

PAGE 57

Hazard Assessment/Risk Analysis: The hazard associated with the mechanical bull ride is sustaining trauma as a result of being thrown from the ride. The risk, or probability of sustaining a severe injury, associated with the hazard depends on the nature of the dismount from the ride, the speed and/or height that the rider falls, and the force created by the landing. Most riders fell from the bull; however, the majority of riders did not sustain serious injury as a result of the ride. Figure 3. is a graphical representation of the ride termination analysis indicating that most riders fall from the bull.

Design Options: In these engineers' opinion it is impossible to remove (or design out) the hazard of being thrown from the bull without also removing the essential characteristics of a mechanical bull ride. A mechanical bull ride is designed to replicate the experience of riding a real bull. Real bull rides regularly result in the rider being thrown off of the bull, and the rider can become severely injured by the fall.

Guarding Options: In this case the plaintiff essentially alleged that the risk associated with falling from the mechanical bull should have been mitigated through the use of an air mattress rather than the vinyl covered foam padding used. The plaintiff apparently based this claim on the fact that other bull ride manufacturers or operators utilize an air mattress rather than the foam mattress. The plaintiff did not provide any other substantial basis for this claim.

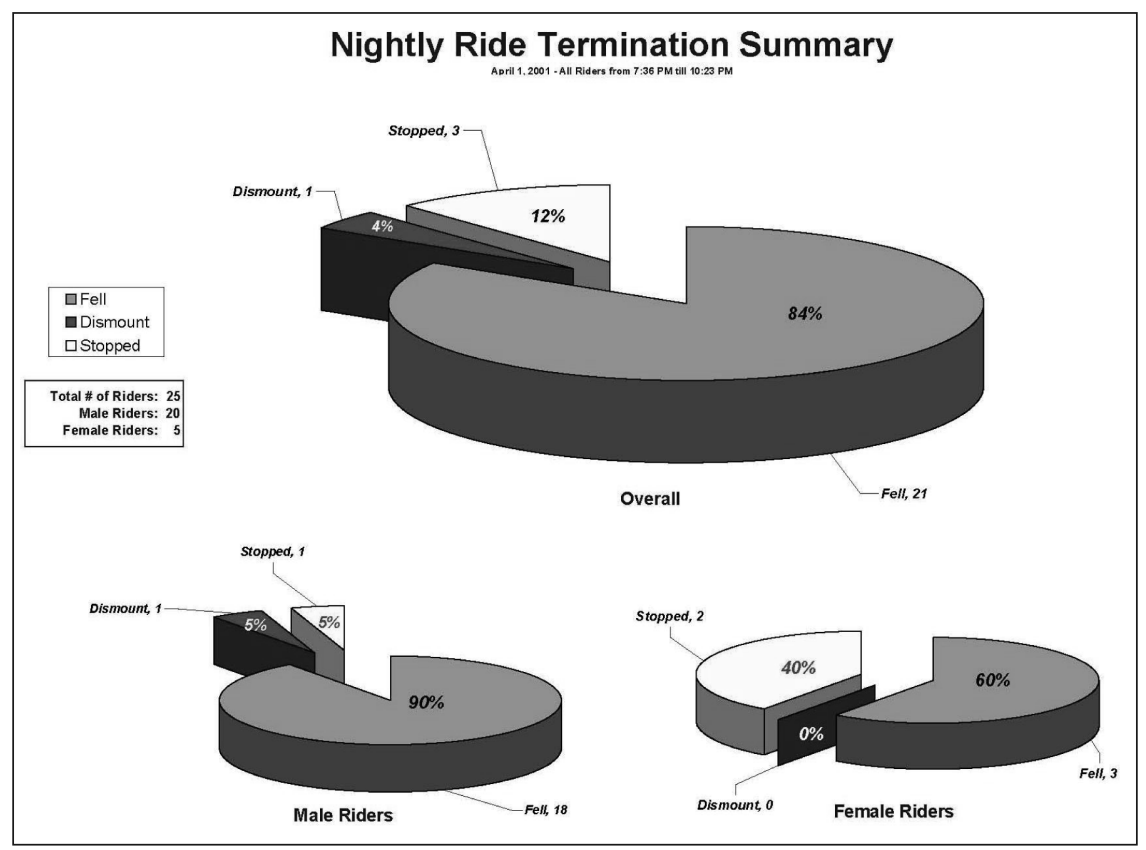

Figure 3

Analysis of Ride Termination 

Copyright @ National Academy of Forensic Engineers (NAFE) http://www.nafe.org. Redistribution or resale is illegal.
Originally published in the Journal of the NAFE volume indicated on the cover page. ISSN: $2379-3252$

These engineers reviewed medical records for the plaintiff which indicated that the plaintiff did not sustain any symptoms of a head injury as a result of the incident. These engineers further performed analysis to determine the head injury criteria (HIC) values that would have likely been generated during the incident based on analysis of the surveillance video of the incident. Because the plaintiff did not sustain a head injury, and the low HIC values associated with the incident, these engineers concluded that the foam padding significantly reduced the force applied to the plaintiff and his head during his landing.

Further, research literature available regarding foam padding, head injury, and neck injury indicated that a "pocketing" mechanism can develop where the head of a person can become trapped in a crash pad or landing pad when the pad is too compliant. When the head of person landing on a crash pad becomes trapped in a pocket, the torso can translate relative to the head leading to serious spinal injuries. Therefore, these engineers concluded that a more compliant mattress might actually increase the number of injuries associated with the bull ride.

Since the plaintiff was essentially alleging that the mattress was not compliant enough, but did not sustain a head injury these engineers concluded that additional padding or the use of an air mattress would not have significantly reduced or eliminated the injury. Further, the use of an air mattress may have generated additional injuries on the bull ride.

Warning Options: Prior to riding the mechanical bull the plaintiff signed a liability waiver that stated the following:

"I understand that there are serious risks to any mechanical bull ride, including this Ride, which risks may include injury, permanent disability, disfigurement, or death."

The waiver signed by the plaintiff met several of the criteria of a good warning label. The warning was conspicuous in that the plaintiff was physically in contact with the warning prior to riding the bull. The warning was informative by indicating that the risks of the ride include injury, permanent disability, disfigurement or death. Another paragraph of the waiver forces the rider to acknowledge that they are riding the mechanical bull of their own free will which indicates that the rider is accepting the risk associated with the ride, and can choose not to ride the ride if they wish. Based on analysis of the waiver, these engineers concluded that the warnings associated with the bull ride were adequate.

Conclusions Case Study \#1: The design intent of a mechanical bull is to simulate the thrill and unique experience of riding a real bull. Therefore, the manufacturer of the bull is well aware of the hazard of injury associated with the 
Copyright @ National Academy of Forensic Engineers (NAFE) http://www.nafe.org. Redistribution or resale is illegal. Originally published in the Journal of the NAFE volume indicated on the cover page. ISSN: 2379-3252

NAFE 308F/713M INVESTIGATIONS OF PRODUCT LIABILITY

PAGE 59

product. If a rider is thrown off of a real bull, a significant risk of injury exists. While the risk of injury has been mitigated on the mechanical bull ride because of the foam padding around the bull, the risk of injury still remains. The use of an alternative air mattress may reduce the risk of injury for some rides; it may increase the risk of injury in others. Because design and guarding options cannot eliminate the hazard from the product, the warnings associated with the product become important. Each rider is required to sign a waiver that indicates that the rider understands the risks, and that the risks include serious injury or death. Therefore, in these engineers' opinions the mechanical bull ride, and foam padding surrounding the ride were not defective.

\section{Case Study \#2 Hydraulic Crane - Electrical Shock Incident}

At approximately 3:00 pm on December 27, 1999, the plaintiff, a construction worker, was guiding a concrete bucket attached to the load line of a rough terrain hydraulic crane in St. Louis, Missouri. As the plaintiff guided the bucket to the desired location the crane operator began to raise the boom of the crane. The boom was located underneath high voltage power transmission lines, and as the crane operator raised the boom the tip of the boom came into contact with the overhead lines. Electric current traveled down the load line electrifying the concrete bucket held by the plaintiff. The current continued to travel through the plaintiff's hand, arm, body, and legs as it completed the path to ground. As a result of the incident the plaintiff sustained serious burns over the majority of his body. As a result of the burns and significant damage to his extremities in the ground path, the plaintiff's arm, and legs were amputated. Figure 4 is a computer generated graphic of the power line and crane.

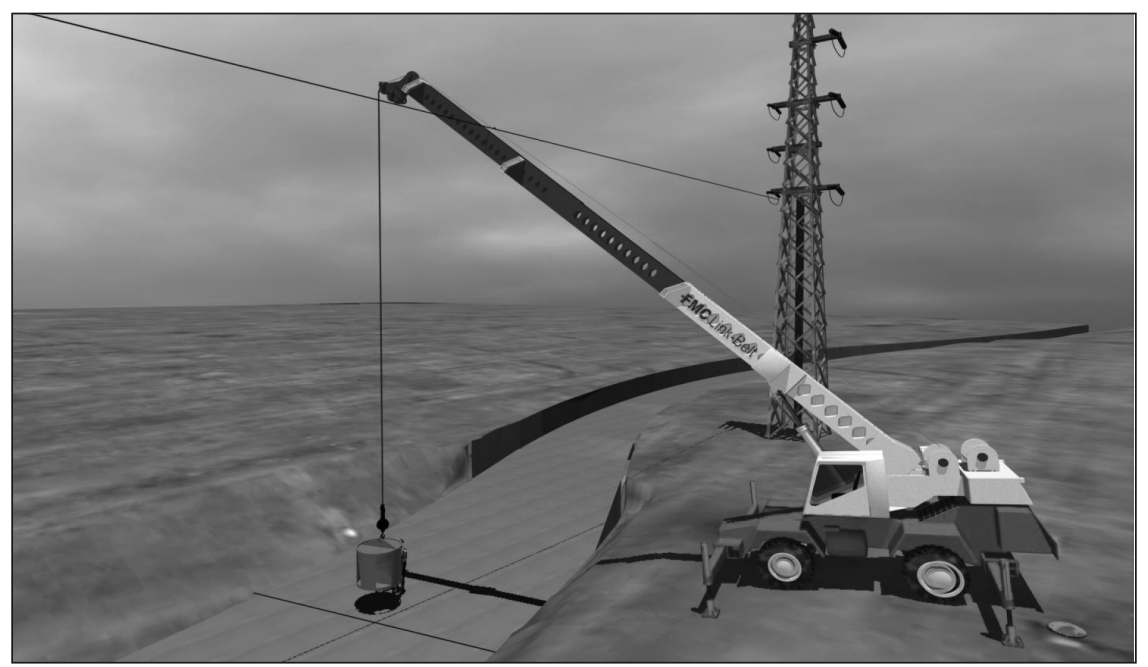

Figure 4

Crane and Power Line at Construction Site 
Copyright $\odot$ National Academy of Forensic Engineers (NAFE) http://www.nafe.org. Redistribution or resale is illegal. Originally published in the Journal of the NAFE volume indicated on the cover page. ISSN: 2379-3252

These engineers were retained to evaluate the design of the crane to determine whether or not the crane was unreasonably dangerous and defective in light of the electrical shock incident involving the crane.

Hazard Assessment/Risk Analysis: The hazard associated with the crane is an electrical shock or electrocution incident as a result of the crane coming into contact with overhead lines. The manufacturer of the crane was aware of the hazard of the crane coming into contact with overhead power lines. Warnings on the crane stated the following:

"Danger! Stay away from machine if close to power lines. Machine, load and ground can become electrified and deadly"

The construction worker in this case was injured when the crane came into contact with an overhead power line and the load, the concrete bucket, became electrified. Although the construction worker lived through the incident in this case the warning and past incidents have shown that cranes coming into contact with overhead power lines can result in fatal accidents. Therefore, the crane manufacturer is aware of the hazard, and the serious consequences that can result.

The risk, or likelihood and severity of injuries associated with power line contact, is well understood. Contact between heavy equipment and power lines regularly occurs and the consequences are serious injury and/or death.

Design Options: The crane in use at the time of the accident was not equipped with any design safety features specifically designed to prevent electrical shock incidents. The crane was equipped with an angle indicator which allows the operator to view the angle of inclination of the boom, and it was retrofitted with an anti-two block alarm/limit switch. The anti-two block alarm sounds and cuts power to the load line winch when the load hook is drawn too far back into the boom.

These engineers identified several technologies that would have prevented the accident, or significantly reduced the probability of the accident. Several crane and bucket truck manufacturers have produced booms that are insulated or composed of non-conducting material. Other crane manufacturers have produced cranes with insulated barriers surrounding the boom of the crane. The most significant technology that these engineers identified that would have prevented this incident (and other accidents) was the use of more advanced controls for the crane operator. The crane in use at the time of the accident was not equipped with any user defined motion limits. The only limits on boom motion were created by the natural limits of the machine. More advanced controls which would limit the angle that the boom could be raised, or the 
Copyright @ National Academy of Forensic Engineers (NAFE) http://www.nafe.org. Redistribution or resale is illegal. Originally published in the Journal of the NAFE volume indicated on the cover page. ISSN: 2379-3252

NAFE 308F/713M

INVESTIGATIONS OF PRODUCT LIABILITY

PAGE 61

distance that the boom could be extended (based on operator input) were available as an option. Such controls would have allowed the operator to preset the maximum angle that the boom could have been raised, which would have prevented the operator from accidentally raising the boom into the power line. The original retail price of the crane in 1984 was $\$ 144,730$. The price of the optional control package would have increased the cost of the crane by less than $5 \%$ which indicates that the control package was not only technically feasible, but was also economically feasible. Therefore, these engineers concluded that design options existed, available from the manufacturer, which would have prevented the accident.

Guarding Options: Because the hazard of cranes coming into contact with power lines has existed for a substantial period of time, multiple guarding solutions have been developed. Two of the guarding solutions identified by these engineers included insulated load line links and a proximity warning device. The insulating link is attached between the load line and the load to protect the construction worker on the ground by preventing electrical current from reaching the load. Insulating links are also available for tag lines used by ground crews to manipulate the load.

Proximity warning devices sense the electromagnetic field associated with power lines. An antenna is placed on the boom of the crane to sense the magnetic field, and a control box in the cab of the crane warns the operator when the boom of the crane is too close to the power line. The proximity warning device guards the crane against the hazard of power line contact by creating space between the power line and the crane. In essence the proximity warning device "guards by location."

Proximity warning devices and insulating links represent at least two guarding options that would have prevented the electrical shock incident. Design options are always preferable to guarding options; however, multiple layers of safety may be beneficial in this case.

Warning Options: The crane was equipped with multiple warnings that power line contact could result in serious injury of death. Warnings are not an acceptable substitute for design and guarding options when the design and guarding options are more likely to prevent serious injuries or deaths. Therefore, these engineers concluded that the warnings on the crane were an inadequate substitute for the safety options available to the crane manufacturer.

Conclusions Case Study \#2: Crane power line contacts occur on a relatively frequent basis. Crane manufacturers are aware of this hazard, and the serious consequences to workers that are electrocuted or electrically shocked when 
Copyright @ National Academy of Forensic Engineers (NAFE) http://www.nafe.org. Redistribution or resale is illegal. Originally published in the Journal of the NAFE volume indicated on the cover page. ISSN: 2379-3252

the contact occurs. Design and guarding options exist that are technically and economically feasible for the crane manufacturer to implement. Power line contacts still occur when warnings are in place on the cranes. Therefore, crane manufacturers could have designed a safer piece of equipment to prevent the electrical shock incident that occurred in this case study.

\section{Bibliography}

1. Weinstein, Alvin S., Aaron D. Twerski, Henry R. Piehler, and William A. Donaher. Products liability and the reasonably safe product a guide for management, design, and marketing. New York: Wiley, 1978.

2. Safety of Machinery - Basic concepts, general principles for designPart 1: Basic terminology, methodology. ISO 12100-1:1992. Genève, International Organization for Standardization, 1992.

3. Control of Hazardous Energy Lockout/Tagout and Alternative Methods. ANSI/ASSE Z244.1-2003. Des Plaines, American Society of Safety Engineers, 2003

\section{Note}

1. While the authors have made a reasonable attempt to provide accurate information, the authors are not attorneys and this paper does not constitute legal advice.

\section{Acknowledgement}

The authors would like to gratefully acknowledge the contributions of Dr. John Palmer, P.E. (NAFE 721M) for his contributions to this paper and the work he performed in the crane power line contact incident. 